\title{
Erratum to: The use of a flat hydrostatic support in the tricycle walking mechanism of a dragline excavator
}

\author{
Nikolay Suslov ${ }^{1}$, and Stanislav Chernukhin ${ }^{1}$ \\ ${ }^{1}$ Ural State Mining University, 620144, Kuibyshev st., 30, Ekaterinburg, Russia
}

Original article:

E3S Web Conf.

Volume 177, 2020

XVIII Scientific Forum "Ural Mining Decade” (UMD 2020)

https://doi.org/10.1051/e3sconf/202017703016

The title of the article should be replaced by the following text:

The use of a flat hydrostatic support in the tricycle walking mechanism of a dragline excavator 